\title{
AS LÓGICAS INSTITUCIONAIS NO CAMPO ORGANIZACIONAL CIRCO CONTEMPORÂNEO: UMA ETNOGRAFIA MULTISSITUADA NO CONTEXTO BRASIL-CANADÁ
}

\author{
INSTITUTIONAL LOGICS IN THE ORGANIZATIONAL FIELD OF CONTEMPORARY CIRCUS: AN MULTI- \\ SITE ETHNOGRAPHY IN THE CONTEXTS OF BRAZIL AND CANADA
}

LAS LÓGICAS INSTITUCIONALES EN EL CAMPO ORGANIZATIVO DEL CIRCO CONTEMPORÁNEO: UNA ETNOGRAFÍA MULTISITUADA EN EL CONTEXTO BRASIL-CANADÁ

\author{
JOSIANE SILVA DE OLIVEIRA \\ Doutora \\ Universidade Federal de Goiás - Brasil \\ oliveira.josianesilva@gmail.com \\ CRISTIANE MARQUES DE MELLO \\ Doutora \\ Faculdade Integrado de Campo Mourão - Brasil \\ mellcris@gmail.com \\ Submetido em:30/06/2016 \\ Aprovado em:07/11/2016 \\ Doi: alcance.v23n4.p475-494
}

\section{RESUMO}

Objetivamos neste artigo analisar as lógicas institucionais na formação do campo organizacional do circo contemporâneo no contexto brasileiro e canadense. Para tanto, realizamos uma articulação teórica entre o conceito de lógicas institucionais e a formação do campo organizacional circense contemporâneo, a partir de uma etnografia multissituada realizada no Brasil com uma organização circense brasileira, e no Canadá, com os circenses da província de Quebeque, em 2013. Os principais resultados enfatizam as lógicas institucionais profissionais, estatais e de mercado como proeminentes nos campos organizacionais circenses em estudo, entretanto vinculadas a diferentes práticas de trabalho em cada país pesquisado devido às diferenças culturais, sociais e organizacionais destas localidades. Apresentamos um caminho teórico e metodológico de estudo das organizações culturais e artísticas que têm incorporado diferentes práticas de gestão em sua constituição, o que deve ser pensado em outros contextos organizacionais como forma de compreensão das relações entre cultura, organização, mercado e Estado.

Palavras-chave: Lógicas institucionais. Etnografia multissituada. Circo.

\section{ABSTRACT}

This article aims analyzes the institutional logics in the formation of the organizational field of contemporary circus in the Brazilian and Canadian contexts. For this, we formed a theoretical link between the concept of institutional logics and the formation of the organizational field contemporary circus, based on a multi-site ethnography in Brazil, with a Brazilian circus organization from the state of Rio Grande do Sul, and in Canada, with the circuses of the province of Quebec, in 2013. The main 
results emphasize the professional, state and market institutional logics as prominent in the organizational fields of circus studied, though linked to different working practices in each of the two countries studied, due to cultural, social and organizational differences between them. We present a theoretical and methodological approach to the study of cultural and artistic organizations that have incorporated different management practices into their constitutions, which should be thought of in other organizational contexts as a means of understanding the relationship between culture, organization, market and state.

Keywords: Institutional Logics. Ethnography multi-site. Circus.

\section{RESUMEN}

El objetivo de este artículo es analizar las lógicas institucionales en la formación del campo organizativo del circo contemporáneo dentro del contexto brasileño y canadiense. Para ello realizamos una articulación teórica entre el concepto de lógicas institucionales y la formación del campo organizativo circense contemporáneo a partir de una etnografía multisituada realizada en Brasil con una organización circense brasileña, y en Canadá con los circenses de la provincia de Quebec, en 2013. Los principales resultados destacan las lógicas institucionales profesionales, estatales y de mercado como prominentes en los campos organizativos circenses en estudio, pero vinculadas a diferentes prácticas de trabajo en cada país investigado debido a las diferencias culturales, sociales y organizacionales de estas localidades. Presentamos un camino teórico y metodológico de estudio de las organizaciones culturales y artísticas que han incorporado diferentes prácticas de gestión en su constitución, lo que debe ser pensado en otros contextos organizativos como forma de comprensión de las relaciones entre cultura, organización, mercado y Estado.

Palabras clave: Lógicas institucionales. Etnografía multisituada. Circo.

\section{INTRODUÇÃO}

A vertente institucionalista tem sido fonte para desenvolvimento de muitas pesquisas na área de Estudos Organizacionais em âmbitos nacional e internacional, entretanto, Suddaby (2010) ressalta que pouco esforço tem sido dispendido pelos pesquisadores institucionais para compreender como as instituições funcionam por meio da influência e da agência dos atores sociais. Do nosso ponto de vista, uma promissora abordagem institucional para explicação da agência, refere-se às lógicas institucionais. As lógicas institucionais estabelecem uma ligação entre a agência e a cognição do indivíduo e as práticas institucionais socialmente construídas e estruturas de regras. A abordagem de lógicas institucionais prevê uma explicação sobre como as instituições, por meio de suas lógicas subjacentes de ação, formam heterogeneidade, estabilidade e mudança nos atores sociais (THORNTON \& OCASIO, 2008).

As lógicas institucionais funcionam como coordenadoras da realidade organizacional, e isto ocorre por meio de regras, práticas e entendimentos compartilhados (LAWRENCE \& PHILLIPS, 2004) entre os membros da organização. $O$ estudo dos elementos imersos no ambiente contribui para 0 entendimento das lógicas predominantes em uma organização, setor, profissão e/ou grupo de atores sociais. A abordagem de lógicas institucionais volta a atenção dos pesquisadores para as estruturas sociais amplas de recursos e de significados (LOUNSBURY, 2007). Tais aspectos estão atrelados às lógicas predominantes e subjacentes à ação e ao comportamento de uma determinada coletividade. Dessa perspectiva, a abordagem de lógicas institucionais pode ser utilizada para o estudo dos mais diferentes tipos e processos organizativos, a exemplo do campo organizacional das artes circenses. 
O circo é considerado como uma arte milenar. Caracterizado por uma estrutura nômade e familiar, no século XX que os circos alteram estas práticas de organização (PARKER, 2011), estabelecendo distinções entre os circos "tradicionais" e "contemporâneos". Os circos contemporâneos rompem com o arquétipo do circo familiar, especialmente nos modos de vida e na transformação dos códigos estéticos. Araújo (2005) discute que o "circo contemporâneo" tem como especial referência as práticas de organização do Cirque du Soleil (Canadá) com o desenvolvimento de uma forma híbrida de circo articulado com teatro, música, dança, práticas econômicas e de gestão empresarial para 0 financiamento de suas atividades (LESLIE \& RANTISI, 2011).

Tendo em vista que o circo contém uma abordagem híbrida no que se refere ao desenvolvimento e à disseminação das diferentes formas artísticas imersas em seu campo, o ímpeto para a realização da presente pesquisa está em verificar a presença de múltiplas lógicas institucionais.

Nesse contexto, apresentamos como problema de pesquisa a seguinte questão: como múltiplas lógicas institucionais são articuladas na constituição do circo contemporâneo? Para tanto, realizamos um estudo etnográfico no Canadá e no Brasil com o intuito de discutir como as lógicas institucionais dos circos nesses dois contextos culturais sustentam o desenvolvimento dos circenses contemporâneos. Essas discussões estão estruturadas nesse artigo em cinco seções, além desta introdução. Primeiramente, discutimos o conceito de lógicas institucionais e a formação do campo organizacional do circo contemporâneo. A seguir, apresentamos os procedimentos metodológicos seguido das análises das pesquisas realizadas no Brasil e no Canadá. A sexta seção é dedicada às discussões comparativas das lógicas institucionais predominantes em cada contexto cultural e as contribuições que esta pesquisa apresenta aos Estudos Organizacionais.

\section{LÓGICAS INSTITUCIONAIS}

Os estudos sobre lógicas institucionais têm enfatizado a heterogeneidade do campo institucional, especialmente no que se refere ao comportamento e às ações dos indivíduos e dos atores organizacionais em contextos pluralísticos. A proposta teórica de estudos sobre as lógicas institucionais foi desenvolvida inicialmente em um artigo de Friedland e Alford (1991). De acordo com os referidos autores, as lógicas institucionais são práticas e sistemas simbólicos da significação da experiência da relação espaço-tempo que ordena a realidade, sendo que diferentes experiências produzidas na sociedade são produzidas pelo sistema interinstitucional no qual diferentes lógicas estão imbricadas em sua constituição. Nesse sentido, as práticas e os sistemas simbólicos serão discutidos e elucidados durante 0 desenvolvimento do presente trabalho, considerando o contexto circense para explicação dos mesmos.

Os principais setores institucionais da sociedade (família, religiões, profissões liberais, Estado, organização e mercado) fornecem um distinto conjunto de lógicas conflitantes e/ou complementares que formam a base de conflito e a conformidade institucional (THORNTON, 2002). Para Friedland e Alford (1991) as principais instituições da sociedade possuem uma lógica central que pode restringir 0 comportamento individual, mas também apresentar-se como fonte de agência e mudança. Isso quer dizer que tal lógica exerce influência, mas também é influenciada pelo comportamento dos indivíduos.

Friedland e Alford (1991) destacam às análises institucionais uma forma de compreensão das relações entre estrutura e agência não pautada em uma perspectiva utilitarista e racionalista, dominante até aquele momento no campo de pesquisa, mas enfatizando as relações interinstitucionais e como isto afeta a ação e o comportamento dos indivíduos e dos atores organizacionais. Ainda de acordo com os referidos autores, os campos organizacionais podem possuir suas lógicas próprias sem que isso resulte em um entendimento hierárquico de suas relações imbricadas com outras instituições da sociedade. 
Apesar dessa definição não ser plenamente aceita no campo de estudos da Teoria Institucional, visto suas limitações em termos teóricos e empíricos, ela foi uma primeira tentativa teórica para avançar nas discussões sobre a dualidade estrutura e agência, especialmente por uma via de discussões que destacassem as ambiguidades e as contradições das ações dos indivíduos e dos atores organizacionais. Thornton e Ocasio (2008) avançaram nesses debates ao definirem as lógicas institucionais como sendo socialmente construídas, com padrões históricos de símbolos culturais e práticas materiais, incluindo suposições, valores e crenças, pelo qual os indivíduos e as organizações dão sentido à sua atividade diária, organizam as relações espaço/tempo e se reproduzem socialmente. Os referidos autores ainda apresentam o nível analítico das lógicas institucionais como sendo o relacional, ao destacarem que o objetivo destas discussões é compreender as inter-relações entre as instituições, indivíduos e organizações em sistemas sociais, e enfatizam três dimensões de análises das lógicas institucionais, quais sejam: estrutural (coercitiva), normativa e simbólica (cognitiva).

Thornton, Ocasio e Lounsbury (2012) afirmam que o sistema social é composto por múltiplas instituições que, no Ocidente, podem ser sintetizadas por meio de setes tipos ideais (tendo por base as discussões de Max Weber): família, religião, estado, mercado, profissões, corporações e comunidade. Para os autores, cada ordem institucional desenvolve suas racionalidades que compõem suas lógicas institucionais. Embora as definições de lógicas institucionais possam variar em sua ênfase, elas pressupõem uma meta-teoria central: para entender o comportamento individual e organizacional, deve-se compreender o contexto social e institucional que tanto regulariza comportamentos como oportuniza a agência e a mudança (THORNTON \& OCASIO, 2008).

Um aspecto importante enfatizado por Thornton, Ocasio e Lounsbury (2012) é considerar os sistemas de significação das ações, bem como as práticas materiais que constituem as lógicas institucionais, destacando para os debates, além das discussões sobre estrutura e agência, os aspectos sobre o duplo empírico/transcendental, objetividade/subjetividade das ações sociais nos campos organizacionais. Com efeito, o foco dos autores se amplia da capacidade de reprodução da instituição para as práticas que podem alterar as relações interinstitucionais, portanto enfatizando a dinâmica da agência e aspectos socioculturais, visto que mais do que respostas institucionais, as lógicas são constituídas por significados, valores, linguagens e compreensões da realidade social produzidas e compartilhadas em um campo (THORNTON; OCASIO \& LOUNSBURY, 2012). Sendo assim, cada instituição desenvolve suas racionalidades e essa dinâmica não se limita ao plano de análise subjetivo, mas incorpora, também, a dimensão da materialidade das organizações, enfatizando, por exemplo, a arquitetura organizacional como componente e efeito das lógicas institucionais.

Com o objetivo de desenvolver teoricamente o conceito de lógicas institucionais, Thornton, Ocasio e Lounsbury (2012) propõem cinco princípios de análise: da agência imersa; da sociedade como sistema interinstitucional; das fundações material e cultural das instituições; das instituições como múltiplos níveis; e o princípio da contingência histórica. O primeiro princípio é o da agência imersa. Esse princípio afirma que as lógicas institucionais são resultado da interação entre agência individual e estrutura institucional. Embora a ação individual e organizacional seja incorporada às instituições, estas são socialmente construídas a partir destas mesmas ações. Com efeito, os referidos autores destacam a necessidade de avanço em estudos que evidenciam como estes planos de análise são imbricados e não hierárquicos. $O$ segundo princípio destaca a sociedade como um sistema interinstitucional. Existem diferentes e contraditórias lógicas nas diversas ordens institucionais resultando na heterogeneidade das ações dos indivíduos e atores organizacionais, visto que estes se constituírem a partir das interconexões entre estas diversas instituições (THORNTON; OCASIO \& LOUNSBURY, 2012).

O princípio das fundações material e cultural das lógicas institucionais postula que as instituições se desenvolvem e mudam como resultado das relações entre estas duas forças. Isso reforça uma das principais contribuições das análises das lógicas institucionais, já indicada nesse artigo, de tentativa de superação da dicotomia empírico-transcendental, ou objetividade/subjetividade, 
característica das Ciências Sociais. As instituições são efeitos de suas materialidades e simbolismos de forma imbricada. Costa e Mello (2012) destacam que essa abordagem diferencia-se de concepções centradas na internalização consciente de valores ou de perspectivas que ressaltam enfaticamente dependência de recursos e interesses políticos.

O quarto princípio é das instituições como múltiplos níveis. Como uma metateoria, a abordagem de estudos das lógicas institucionais possibilita a realização de pesquisas com base em vários níveis de análise, por exemplo nos estudos sobre organizações de mercados, indústrias, redes interorganizacionais, comunidades geográficas e campos organizacionais. As lógicas institucionais diferem das lógicas de ação, sendo a segunda relacionada às práticas individuais e não às de relações interinstitucionais. O quinto princípio destacado por Thornton, Ocasio e Lounsbury (2012) é a contingência histórica. Esse pressuposto centra a atenção em como macroambientes afetam 0 comportamento individual e organizacional a partir de uma perspectiva longitudinal.

Thornton, Ocasio e Lounsbury (2012) propõem que as articulações entre as diferentes lógicas que constituem as ordens institucionais podem resultar em diferentes práticas organizacionais, visto a heterogeneidade e as contradições inerentes às lógicas das diversas ordens institucionais. Especialmente no campo artístico existe um debate sobre a predominância dos tipos de racionalidades no trabalho com artes (SOUZA \& CARRIERI, 2011), ou seja, existe uma discussão dicotômica sobre a predominância de lógicas institucionais de profissionais e de mercado nos campos organizacionais artísticos.

Thornton (2002) salienta que estudos de caso têm mostrado que a lógica institucional imersa nas profissões é contraditória com objetivos e meios de controle da organização. As profissões são organizadas de modo que seus membros criam conhecimento e sistemas de crença que definem áreas de interesse e competência. No que se refere às lógicas de mercado, estudos têm demonstrado como a lógica institucional de mercado é complementar aos objetivos das organizações. As diferentes condições de mercado determinam quais estratégias organizacionais e estruturas estão propensas de serem adotadas para resolver seus problemas (THORNTON, 2002).

Sobre diferentes lógicas institucionais em um mesmo campo organizacional, Reay (2009) destaca três explicações predominantes na literatura, sendo elas: (1) entre as múltiplas lógicas sempre uma será dominante e guiará o comportamento dos atores sociais; (2) a diversidade de lógicas terá como efeito a formação de um campo de disputas para que uma prevaleça; (3) várias lógicas institucionais podem coexistir e ter diferentes impactos sobre os diversos atores considerando aspectos contextuais, a exemplo de questões geográficas.

Reay (2009) afirma que na primeira forma de conceituar a relação entre múltiplas lógicas, em que uma será sempre dominante, o trabalho de Scott et al. (2001) pode contribuir com estas discussões, pois enfatiza como lógicas consideradas secundárias em um campo organizacional alteram a mudança das lógicas dominantes, constituindo-se como fontes de mudanças. $O$ autor atenta para 0 fato de que estudos sobre a dinâmica das lógicas secundárias ainda são incipientes em Estudos Organizacionais. $\mathrm{O}$ foco em uma lógica dominante dentro de uma profissão ressalta a atenção dos atores sociais com essa lógica e assume consenso entre os profissionais (DUNN \& JONES, 2010), 0 que pode limitar os debates sobre os conflitos de lógicas na constituição das profissões.

$\mathrm{Na}$ segunda perspectiva de estudos sobre lógicas institucionais discutida por Reay (2009), no campo organizacional em que há uma diversidade de lógicas, a disputa entre as mesmas ocorre até que uma delas predomine, tornando-se dominante por um período de tempo. A diferença entre essa concepção e a anterior é que nessa o foco está nas lógicas concorrentes, mas sem destaque para uma lógica vencedora (REAY, 2009).

A terceira abordagem de estudos sobre lógicas institucionais destacada por Reay (2009) tem buscado discutir como a multiplicidade de lógicas podem estar associadas a diferentes atores, 
comunidades geográficas ou organizações, ou seja, destaca-se como diferentes contextos culturais podem produzir diferentes lógicas institucionais nos campos organizacionais. Esta abordagem em particular nos interessa, tendo em vista o foco da presente pesquisa e o objetivo inicialmente proposto para o desenvolvimento do estudo (REAY, 2009).

A fim de elucidar para o leitor o campo investigado, na próxima seção deste trabalho discutiremos, de forma ampla, a formação do campo organizacional do circo contemporâneo e as possibilidades de compreensão de como diversos contextos culturais fomentam distintas práticas dos artistas de circo.

\section{O CAMPO ORGANIZACIONAL DO CIRCO CONTEMPORÂNEO}

As artes circenses são milenares, entretanto passaram a ser discutidas como um campo organizacional e de trabalho na sociedade ocidental contemporânea, a partir do século XVIII na Inglaterra, durante o período da Revolução Industrial (PARKER, 2011; OFEN, 2010). O circo se estruturou a partir de uma dinâmica itinerante, e a continuidade do trabalho nas organizações circenses dependia em grande medida da formação familiar e na transmissão entre gerações das técnicas circenses. $O$ processo de aprendizagem das técnicas circenses ocorria no próprio cotidiano do circo, em que, por meio da oralidade, os saberes eram transmitidos entre os sujeitos que faziam parte destas organizações sem a necessidade de frequentarem escolas com essa especialidade. Então era muito comum a composição de circos a partir de nomes de famílias, pois o núcleo familiar responsável para transmissão e manutenção das práticas do circo de "pais e mães" para os filhos e filhas. Os trailers eram as casas dos artistas e profissionais circenses, em geral, instalados ao redor da lona central (SACCHI, 2009). A opção pela residência em traillers ocorria devido à itinerância destas organizações, que migravam constantemente em busca de novos públicos para seus espetáculos.

A partir dos anos de 1960, conforme destaca Garcia (2011), houve uma crise no circo "tradicional", especialmente devido ao crescimento da indústria do cinema e dos festivais de grandes espetáculos. Os circos então começaram a participar desses festivais artísticos, especialmente na França, e, para isso, iniciaram um processo de incorporação da dramaturgia cênica nos espetáculos. 0 processo de divisão do trabalho passa a ser desenvolvido semelhante ao do teatro, como uma das principais características a autonomia do diretor em cena, e não mais entre os núcleos familiares circenses. Assim sendo, tem-se um processo de separação entre criação e interpretação na produção dos espetáculos circenses que não se restringia somente à família que compunha o circo, sendo diversas tarefas, a exemplo da produção dos espetáculos, delegadas a produtores culturais, ou sujeitos que não eram do circo (GARCIA, 2011).

Essa tensão da divisão do trabalho se articula com a formação de escolas de profissionalização dos artistas circenses rompendo com os processos de aprendizagem centrados na transmissão oral (FAGOT, 2010). Com isso, outra distinção se estabelece no cotidiano circense: os discursos sobre o circo "tradicional" e o "contemporâneo" (FAGOT, 2010). Fargot (2010) destaca que 0 "novo circo" ou o "circo contemporâneo" rompe com o arquétipo do circo familiar e na transformação dos códigos estéticos, a exemplo da não utilização de animais nos espetáculos. Ainda para o autor, esse rompimento fortalece o discurso sobre a classificação do circo como "tradicional" e "contemporâneo" de forma pejorativa, pois traz a ideia de qualificadores de desvalorização, sendo o "novo" ou o "contemporâneo" como mais adequados às atuais formas de produção artística, a exemplo da profissionalização dos modos de fazer dos artistas circenses.

Bouissac (2012) afirma que essa separação entre o circo "tradicional" e "contemporâneo" ocorre, especialmente, pois o "circo contemporâneo", ao contrário do primeiro, pautado em tradição familiar, "vai à escola" pela "descoberta" do circo como saber técnico. E são as técnicas circenses que se tornam base de expressão artística na produção do espaço organizacional circense 
"contemporâneo". Como um "saber", as técnicas circenses puderam, então, ser entrelaçadas com outros "saberes", a exemplo das técnicas desportivas, dança, dentre outras (BOUISSAC, 2012).

As escolas de circo, fora da tradição familiar, se estabeleceram de forma mais intensa no Ocidente, a partir de 1980, especialmente na França e no Canadá (FAGOT, 2010). De acordo com Garcia (2011), nas escolas de circo a seleção dos artísticas passou a ter como eixo central a forma física dos sujeitos. Após serem aceitos, os intensos treinamentos físicos ensinam os artistas a conviverem com a dor, a repetição incansável de gestos, movimentos e posturas (GARCIA, 2011).

Nas palavras de Araújo (2005), esse movimento de incorporação de outras práticas à produção dos espetáculos circenses tem como referência as práticas de organização do Cirque du Soleil (Canadá), que tem desenvolvido uma forma hibrida da arte circense que articula circo, teatro, música, dança, práticas econômicas e de gestão para o financiamento de suas atividades (LESLIE \& RANTISI, 2011) com uma estrutura organizacional empresarial que remete à divisão social e formal do trabalho. Os artistas também não residem mais em trailers e nos circos, por isso, a existência de centros de treinamentos (CT) e escritórios que cuidam da produção executiva dos espetáculos.

Esse processo organizativo circense canadense tem sido utilizado como referência de práticas para o "circo contemporâneo" (LESLIE \& RANTISI, 2011). No Canadá, o "circo contemporâneo" começa a se consolidar no início da década de 1980, quando é fundada a primeira escola de circo canadense com foco no desenvolvimento técnico da arte associada com a ginástica (ÉCOLE NATIONALE DE CIRQUE, 2013). Desde então, o circo canadense tem se desenvolvido e sido reconhecido internacionalmente pela destreza técnica, advinda do desenvolvimento desportivo dos artistas circenses, e pelo acesso de pessoas não ligadas tradicionalmente às artes circenses e à aprendizagem do circo em escolas.

A cidade de Montréal, província de Quebeque, no Canadá, é uma das principais localidades do mundo em que o circo se consolidou como uma importante cadeia de produção artística associada à dimensão econômica de desenvolvimento urbano. Estima-se que aproximadamente 4000 são empregadas em atividades relacionadas ao circo na cidade de Montréal, província de Quebeque, 26 escolas ou organizações especializadas em circo, sendo 15 destas na província de Quebec; e dos 300 difusores das artes circenses pelo mundo, destes 127 estão somente em território quebequense (SAIRE; DALGIE, 2012).

Diante do que foi exposto, entendemos que os circos se apresentam como um contexto ambiental rico para o estudo de lógicas institucionais. A identificação com o coletivo é equivalente à identificação com a lógica institucional, sejam de formas organizacionais ou associações profissionais, ou qualquer outro grupo social (THORNTON \& OCASIO, 2008).

\section{PERCURSO METODOLÓGICO}

O método de pesquisa utilizado foi a etnografia multissituada (MARCUS, 1999) no Brasil e no Canadá. No Brasil, a pesquisa foi desenvolvida entre os meses de março e dezembro do ano de 2011 com um circo contemporâneo localizado na cidade de Pelotas, Rio Grande do Sul, fundado no ano de 1987 e tombado como patrimônio cultural gaúcho no ano de 2007. Da etnografia (CLIFFORD, 2008) se destacaram as observações participantes descritas em diários de campo, em um total de 70, e entrevistas semiestruturadas realizadas com os 32 artistas circenses que constituem a trupe. Também foi realizada pesquisa documental em revistas e jornais da cidade de Pelotas sobre 0 circo em estudo desde a sua fundação, além de dados secundários disponibilizados pelo IBGE (Instituto Brasileiro de Geografia e Estatística) sobre as artes circenses no país.

A partir desta pesquisa inicial, foi possível identificar que a principal referência de organização dos artistas de circo no Brasil era o contexto canadense e, por isso, optou-se por desenvolver a 
etnografia também na cidade de Montréal, Canadá, de forma a compreender como as lógicas institucionais do campo organizacional do circo circulam e são contextualizadas em diferentes conjunturas socioculturais.

Tendo em vista que nos estudos etnográficos o pesquisador tem a intenção de interpretar e descrever significados velados nas práticas sociais de um grupo (MELLO, 2014), o estudo de lógicas institucionais por meio desse método é pertinente porque é também intenção da abordagem institucional oferecer atenção intensificada aos aspectos simbólicos da vida social (SCOTT, 2001), que podem ser identificados em suas práticas.

Para a coleta de dados no Canadá, a etnografia baseou-se nas seguintes técnicas de coleta de dados: pesquisa em documentos disponibilizados pelas organizações, entrevistas com roteiro semiestruturado e observações diretas (FONTANA \& FREY, 2005). Foram entrevistados os gestores das três organizações canadenses responsáveis pela formação, desenvolvimento e difusão das artes do circo no Canadá. As temáticas do roteiro das entrevistadas versavam sobre (1) a história do circo em Montréal; (2) as fontes de financiamento para os circenses; (3) os programas de fomento as artes do circo; (4) a participação do Estado e de empresas no fomento das atividades das organizações; (5) as principais companhias circenses no campo organizacional do circo no Canadá.

A partir destas entrevistas, foram identificadas dez principais companhias de circo contemporâneo naquele país, sendo possível entrevistar gestores de 7 destas organizações. Todas as entrevistas foram previamente agendadas com os participantes da pesquisa e realizadas na sede dos circos ou em locais definidos pelos gestores, a exemplo de cafés ou restaurantes. 0 roteiro das entrevistas foi estabelecido a partir de quatro eixos: (1) história de constituição do circo; (2) participação da trupe circense em organizações profissionais relacionadas ao circo; (3) processo de entrada no mercado artístico; (4) participação do Estado no campo das artes circenses. As entrevistas foram realizadas na língua francesa. Com essa fase exploratória de pesquisa, identificou-se, a partir dos atores sociais entrevistados, o circo com maior influência política no contexto canadense, para o qual foi realizada a etnografia na cidade de Montreal.

O circo etnografado em Montréal foi fundado no início dos anos 2000, possui atualmente 10 espetáculos produzidos e é considerado pela crítica artística internacional como (re)inventores do circo contemporâneo, ao tematizar em seus espetáculos a constituição do sujeito no contexto urbano contemporâneo. A etnografia foi desenvolvida entre os meses de junho e setembro do ano de 2013. Nesse período foi possível acompanhar o processo de criação e produção de um novo espetáculo pela organização. As observações participantes totalizaram 35 diários de campo e foram complementadas com uma entrevista semiestruturada com o diretor artístico do circo sobre as práticas de organização da trupe em estudo. Sobre a pesquisa documental, foram pesquisados jornais, revistas e documentos sobre a história do circo e os processos de organização dos artistas circenses no Canadá fornecidos pelas organizações pesquisadas, especialmente pela Escola Nacional do Circo de Montréal. Os Conselhos de Artes e Letras do Canadá e da província de Quebeque em conjunto com o Ministério da Cultura canadense disponibilizaram documentos sobre a trajetória de investimentos, políticas e programas do Estado para as artes do circo naquele país.

Sendo assim, na próxima seção deste artigo apresentamos as três lógicas institucionais identificadas com a realização desta pesquisa, sendo estas: lógica profissionalização dos artistas circenses, lógica de mercado para a definição do contexto onde o circo irá atuar e lógica de Estado com base nas políticas públicas e intervenções dos Governos sobre as atividades circenses.

\section{AS LÓGICAS INSTITUCIONAIS NO CONTEXTO BRASILEIRO}


No Brasil, as práticas circenses chegaram ao país por volta do século $X X$ trazidas por imigrantes europeus (ÁVILA, 2008). Nesse período, de acordo com Nepomuceno Filho (2009), a denominação utilizada para os artistas de circo era de mambembe (ator, ou grupo teatral amador e de má qualidade) ou saltimbanco que geralmente eram ciganos. Costa (2009) destaca que a imprensa local brasileira, comprometida com a promoção dos espetáculos "nobres", a exemplo de óperas, incomodava-se com a presença do público em espetáculos populares e menosprezavam os circenses e os seus mecanismos de sobrevivência por meio da produção de sentidos pejorativos aos indivíduos que trabalhavam e assistiam aos espetáculos circenses. A praça pública era o principal espaço utilizado pelos circenses para as suas apresentações (COSTA, 1999).

Costa (1999) descreve três processos organizativos que caracterizavam, no início do século $X X$, os circenses no Brasil: o tapa-beco, o circo de pau fincado e o circo de pau a pique. $O$ tapa beco era em um terreno baldio cercado por duas casas, onde uma das extremidades do espaço era fechada com uma cortina e o público assistia de pé ou levava suas próprias cadeiras. 0 circo de pau a pique era montado com madeiras aparadas em forma de toras ou estacas fincadas no chão formando um círculo. O picadeiro, de acordo Costa (1999), era demarcado com a corda, o público ficava de pé ou trazia as cadeiras de casa e as apresentações, assim como no tapa becos, eram diurnas devido à falta de iluminação. $O$ circo de pau fincado se caracteriza por estacas de madeira fincadas em círculo unidas por um pano - o pano de roda - nas quais também eram fixadas as arquibancadas. Em torno do picadeiro havia um espaço para se colocar cadeiras do circo ou do público. Esse trabalho de montagem era realizado pelos próprios artistas do circo. Dentre estes três processos organizativos dos circos, possuir um circo de pau fincado já significava um certo status diferenciado para a época, apesar de atualmente serem considerados como mais pobres (COSTA, 1999).

O espetáculo circense no início do século XX no Brasil era composto por duas partes. A primeira com números circenses e a segunda com uma peça de teatro. Essa integração com o teatro fez com que 0 espetáculo circense começasse a desenvolver elementos de encenação e de interpretação tendo o palco como outro espaço de sua constituição, além do picadeiro e das praças (COSTA, 1999). Silva (2007) destaca que uma das principais características das "maneiras de fazer" circenses no século XX era sua hibridização com diversos gêneros teatrais e de dança, o que resultava no mútuo diálogo dos circos com os movimentos culturais de sua época.

Rocha (2010) afirma que o circo-teatro tem importância histórica no Brasil, pois é considerado como uma versão nacional e popular do circo no país. Isso porque, por exemplo, se em outros países o que se observava era 0 aumento dos números de palhaços com base em mímicas e gestualidade, no Brasil o palhaço falava, cantava e era considerado como um 'bom malandro'. Além de ser considerado como um veículo de diversão popular, o circo-teatro também apresentava críticas em relação à dinâmica social do país, resultando em sua legitimação no discurso científico como uma manifestação cultural (ROCHA, 2010).

Na segunda metade do século XX, com a diminuição dos circos familiares, o circo-teatro passa por uma crise. $O$ surgimento das escolas de circo, dos festivais mundiais, a exemplo do francês Festival du Cirque Demain, e de diversas companhias, grupos performáticos e trupes de artistas, fomentou o fenômeno do denominado "novo circo" ou "circo contemporâneo" também no Brasil, cuja grande referência de atuação é o circo canadense Cirque du Soleil (ROCHA, 2010).

Fundado na década de 1980 por Pedro, ator e ginasta, o Circo Alegria financiava suas atividades até 0 ano de 2002 por meio de animações em eventos e produção de pequenas apresentações. No ano de 2002 estreia seu primeiro espetáculo já assistido por mais de um milhão de pessoas no Brasil. Atualmente, a organização possui aproximadamente cem pessoas atuando em suas atividades, três espetáculos em cartaz e realiza dois projetos sociais, sendo o circo escola para crianças e adolescentes, bem como desenvolve atividades de animações em instituições sociais em sua cidade sede. 


\title{
5.1 LÓGICAS PROFISSIONAIS: A FORMAÇÃO DOS ARTISTAS CIRCENSES
}

No Brasil, a presença de escolas profissionais de circo ainda é incipiente. Por isso, os circos brasileiros, geralmente, optam por realizar o processo de profissionalização dos artistas dentro das organizações por meio de ofertas de cursos ministrados pelos artistas com mais experiência em circo aos artistas ingressantes na trupe.

No circo Alegria, o processo de ingresso na organização ocorria por meio de oficinas/audições anuais realizadas entre os meses de janeiro e março. Como as atividades fixas no CT dependiam da agenda de viagens do circo, as oficinas não tinham uma data definida para serem realizadas. Essa oficina era preparada pelos artistas do circo. A forma de divulgação era por meio das redes sociais nos ambientes virtuais, publicidade local e contatos pessoais dos integrantes do grupo. As atividades eram desenvolvidas em três fases: atividades físicas, atividades artísticas por meio da apresentação de algum tipo de habilidade com os aparelhos circenses e um luau, cujos candidatos, em sua maioria, ainda não vinculados ao campo das artes, poderiam criar alguma apresentação.

O principal aspecto observado pelo diretor do circo para a seleção de um novo artista não era somente o domínio de uma técnica circense específica, mas a "disposição" dos indivíduos em incorporar as práticas de trabalho presentes no circo que possibilitavam 0 artista ser "produzido" naquele e para aquele contexto. Os produtores culturais atuam nessa dinâmica de forma a articular estas dimensões de produção e profissionalização dos artistas circenses. Essa lógica de formação pode ser observada no seguinte relato do acrobata Pedro sobre sua relação com artistas circense Vanessa:

\begin{abstract}
Então, ela me ensinou muita coisa. Tudo que eu sei de acrobacia aérea hoje foi ela quem me ensinou. Tudo não, mas a minha base toda foi ela. É claro que eu fui procurar a minha linha, os meus caminhos, as minhas referências. Mas, a minha primeira referência foi ela. Então, ela me ensinou muita coisa. Hoje em dia é uma das minhas técnicas mais fortes, o aéreo, foi ela quem me ensinou. Foi ela que "me fez". (PEDRO, ACROBATA, 24 ANOS).
\end{abstract}

Nesse relato é possível observar a relação entre a lógica de profissionalização dos artistas e as práticas de trabalho. O enunciado "foi ela que me fez" era muito comum no circo para indicar quem foi referência na formação dos artistas, indicando como as ações que constituem as relações espaço e tempo na organização no contexto da formação dos artistas de circo são significadas possibilitando a interpretação do cotidiano organizacional (FRIEDLAND \& ALFORD, 1991).

As lógicas profissionais estão vinculadas à forma que os atores sociais criam e promovem conhecimento e sistemas de crença que irão amoldar suas habilidades e áreas de interesse (THORNTON, 2002). No caso em estudo, a disseminação do conhecimento ocorre por meio da troca entre artistas mais experientes e artistas iniciantes, a qual irá refletir nas práticas de trabalho circense. É nessa interação social também que ocorre o compartilhamento de crenças e de valores predominantes na profissão, que podem ou não serem reforçados ou reconstruídos. É importante destacar que no Brasil essa dinâmica ocorre no cotidiano das organizações devido à pouca oferta de cursos profissionais de formação de artista de circo.

\subsection{LÓGICAS DE MERCADO}

A lógica de mercado que sustenta o sistema econômico também interpela as práticas de trabalho do fazer artístico circense, especialmente pelo reconhecimento da necessidade de ampliar mercado para o espetáculo para garantir a sobrevivência da organização. Entretanto os artistas reconhecem que não é somente a lei da oferta e da procura que garante o mercado para as suas 
atividades. Existe a influência de outros fatores, inclusive internacionais, a exemplo do desempenho do Cirque du Soleil no exterior, que garantiria a ampliação do espaço de atuação do circo no país.

A gente vendo o VHS do primeiro espetáculo é muito engraçado. Porque é muito diferente, sabe. Apesar de a trilha ser igual é muito diferente do que é agora. Depois, disso [das estreias dos espetáculos] o Alegria foi crescendo assim [...] Mas, mesmo assim, eram apresentações esporádicas porque o grupo não tinha tanta agenda assim. Não tinha tanto mercado pra isso. (PEDRO, ACROBATA, 24 ANOS).

O entendimento de mercado para os artistas está relacionado à ampliação de seu espaço de atuação e não a uma dimensão unicamente de ganhos econômicos. Por isso, as artes circenses não têm um fim em si mesma, conforme preconizam alguns estudos sobre as organizações artísticas, mas a finalidade é transformar o cotidiano do público, o que somente seria possível se o circo ampliasse seu espaço social de atuação:

\begin{abstract}
E o objetivo são essas pessoas. [...] E essa coisa de mudar alguns minutos a vida de uma pessoa. A gente tá incentivando aquela pessoa em ir mais ao teatro, estimulando aquela pessoa de ter mais contato com a arte ou pensar em fazer alguma coisa com seu corpo ou uma atividade física. [...] E é legal assim quando a gente consegue ir numa plateia inteira de oitocentas pessoas e que uma pessoa pense assim: vou fazer alguma coisa! (JUSTINE, ACROBATA, 26 ANOS).
\end{abstract}

Por isso, a lógica de mercado é entendida pelos artistas não como um processo de transformação dos espetáculos em mercadorias, mas como uma dimensão de atuação política da organização, o que engloba fatores econômicos, sociais e de relações de poder, conforme discutiremos no próximo tópico sobre a relação da organização em estudo com a cidade onde a mesma possui sua sede.

\title{
5.3 LÓGICAS ESTATAIS
}

Apesar de não haver uma regulamentação estatal específica sobre a atuação dos circos no Brasil, outros tipos de regulamentação do Estado influenciam a atuação da organização, especialmente no que se refere à ocupação do espaço urbano que revela as relações de poder e de disputa entre 0 circo e o poder público, conforme pode ser observado no seguinte relato:

\begin{abstract}
A gente teve um momento difícil que foi até no ano passado assim. A gente estava sem um lugar pra treinar sabe. E aí não conseguia ninguém que ajudasse. Procurava, a gente procurava um espaço pra se manter. E não conseguia achar nada em Pelotas, e aí a gente conseguiu um grupo de arquitetos lá em Pelotas, uma ONG, e eu não vou saber dizer o nome da ONG agora, que eles ajudam algumas instituições assim. Tipo, não cobram nada pra fazer o projeto. E aí eles ajudaram. Mostraram até um projeto em um antigo prédio [...] que tinha lá que estava abandonado. E aí fizeram um projeto de um centro cultural, um espaço cultural né, e aí nisso, dentro desse centro cultural teria o teatro [que o circo poderia ensaiar] né. $E$ a gente, bah! Ficou tri empolgado pro negócio dar certo. $E$ aí, entrou na prefeitura esse projeto que foi rolando, e aí foi aprovado e tal, e aí só faltava a assinatura do prefeito. E o prefeito negou. [...] e hoje em dia a gente tem um espaço muito legal e sem custo nenhum. (DIOGO, ACROBATA, 25 ANOS).
\end{abstract}

A ocupação do espaço da cidade é produzida com base nas disputas políticas entre Estado e empresas, por isso a lógica de atuação do Estado em reduzir a participação do circo teve como efeito a aproximação com empresas na cidade, as quais forneceram um espaço sem custos para a atuação da organização circense na cidade. As organizações circenses estão imersas em um ambiente 
institucional e por isso são afetadas pelas instituições que as cercam, inclusive pelo Estado. Esses conflitos com a lógica estatal tinham como principal influência organizacional e interpretação dos artistas de circo o contexto canadense:

\begin{abstract}
Foi quando eu entrei no Grupo e tive contato com o Cirque Du Soleil [que percebeu que o Alegria é um circo]. Tive contato com vídeos e eu: pô! Que massa! E aí a gente sempre teve a pretensão de chegar ao nível do Cirque Du Soleil. E hoje em dia ainda é um pouco isso. Mas, a gente quer botar a nossa cara na verdade. Mas, é ter a fama que ele tem, a grandiosidade que ele tem, o apoio que ele tem do Estado, do Canadá, que apoia muito. É ser reconhecido aqui no Brasil. (DIOGO, ACROBATA, 25 ANOS).
\end{abstract}

Tendo como base esse depoimento, entendemos que o campo organizacional circense do Canadá tem sido referência de atuação para outros circos, porque alcançou legitimidade. Desse modo, há uma tendência de que as práticas de trabalho do circo canadense sejam aceitas e reproduzidas em organizações similares. Na visão de Suchman (1995), a legitimidade é a percepção generalizada de que as ações de uma entidade (organização) são desejáveis (ou apropriadas) em um sistema que é construído socialmente, constituído por normas, valores e crenças. Conforme apontam Dacin, Oliver e Roy (2007), a legitimidade tem tanto funções estratégicas como institucionais.

As práticas do circo canadense são reproduzidas porque suas ações são aceitas socialmente e desejáveis pelos seus pares como práticas estratégicas para se promoverem no campo.

Em uma sociedade moderna, as organizações são impelidas a incorporar novas práticas e procedimentos definidos por prevalecerem concepções racionalizadas de trabalho organizacional e institucionalizada na sociedade. Essas organizações fazem aumentar sua legitimidade e sua sobrevivência, independente da eficácia imediata das práticas e dos procedimentos adquiridos (MEYER \& ROWAN, 1991) e, por isso, desenvolvemos o estudo também no Canadá, o qual é apresentado na próxima seção deste artigo.

\title{
6 AS LÓGICAS INSTITUCIONAIS NO CONTEXTO CANADENSE
}

As primeiras apresentações circenses no Canadá demarcam do final do século XVIII, especialmente na cidade de Montréal. Essas organizações eram essencialmente familiares e provenientes dos Estados Unidos da América ou Inglaterra (BOUDREAULT, 2002). Na província canadense de Quebeque, de colonização francesa, o circo foi introduzido por volta do ano de 1797 por canadenses ingleses, após Quebeque ser integrada ao Império Britânico. Nessa época, de acordo com Boudreault (2002), os teatros foram fechados durante a passagem do circo, tal o impacto social de suas apresentações. No início do século XIX, os circos estabelecidos em Quebeque apresentavam-se em teatros. Os quebequenses não faziam diferenciação entre as disciplinas artísticas, especialmente pelo fato de que como as condições climáticas canadenses com invernos intensos impediam a itinerância dos circos em pelo menos seis meses durante 0 ano. Com efeito, os circenses canadenses se constituíram a partir de apresentações em espaços como o teatro e, portanto, facilitando a expansão do denominado "circo contemporâneo" nessa localidade.

Um exemplo apresentado por Cook (1986) que reflete estas disputas entre ingleses e franceses no contexto canadense de Montreal é o "Grande Circo Ordinário" (1969 - 1977). Pautado em um processo de "criação coletiva", esse circo fazia parte de um movimento de contestação com ideais igualitários e populares com o objetivo de afirmar a "identidade quebequense" (LEGAULT, 2012). 0 "Grande Circo Ordinário" realizava uma aproximação artística entre circo e teatro, mas, também, incorporava outras artes em seus espetáculos desenvolvendo técnicas de criação e de formação artística não hegemônicas (LEGAULT, 2012). 0 "Grande Circo Ordinário" trabalhou, entre os anos de 
1969 e 1971, em conjunto com o Teatro Popular de Quebeque, composto por artistas do Teatro Novo Mundo de Montreal. Sendo assim, a gênese do circo em Quebeque tem uma proximidade com o teatro, seja nos processos criativos ou na ocupação de espaços para apresentações.

No início da década de 1980 é fundada a primeira escola de circo canadense com foco no desenvolvimento técnico da arte associada com a ginástica de tradição russa (ÉCOLE NATIONALE DE CIRQUE, 2013). Desde então, o circo canadense tem se desenvolvido e sido reconhecido internacionalmente pela destreza técnica e pelo acesso de pessoas não ligadas tradicionalmente às artes circenses e à aprendizagem do circo em escolas.

Durante a comemoração do $450^{\circ}$ aniversário da descoberta do Canadá por Jacques Cartier, no ano de 1984, que o Cirque du Soleil, considerado como uma das principais referências em artes do circo atualmente, com sede até então em Quebeque, realiza sua primeira turnê com financiamento do governo quebequense e a produção de um espetáculo circense que articulava circo, teatro, dança e ginastas. Com isso, outros dois aspectos que se destacam no processo organizativo do circo em Quebeque é a sua inserção política e da participação estatal no fomento de suas atividades.

A cidade de Montréal, local da atual sede do Cirque du Soleil, apresenta no circo uma importante cadeia de produção artística e econômica. Estima-se que são gerados mais de 4000 empregos diretos, somente na cidade de Montréal, relacionados às atividades circenses; 26 escolas ou organismos que oferecem atividades especializadas em circo no Canadá, sendo 15 por toda a província de Quebec; 300 difusores responsáveis por divulgar as artes circenses pelo mundo, destes 127 estão no território quebequense (SAIRE \& DALGIE, 2012).

A principal via de fomento destas atividades é o governo da província de Quebeque, que, além de ser o principal financiador das escolas de circo, fomenta a capacitação profissional artística por meio de bolsas a projetos dos artistas, e, também, apresenta linhas especificas de financiamento das atividades das organizações que representam os artistas. Com isso, nessas primeiras análises é possível observar evidências da importância da participação dos poderes públicos no desenvolvimento de (1) políticas de profissionalização dos artistas, especialmente no fomento das escolas de circo; (2) capacitação para o incremento de mecanismos de gestão específico ao domínio artístico por meio do financiamento das atividades da En Piste, e pelo financiamento de projeto e bolsas para os artistas de circo desenvolverem suas atividades, tendo como efeito 0 desenvolvimento econômico destas organizações.

É nesse contexto que, no ano de 2002, o circo Passion foi fundado por sete artistas circenses (Julie, Louise, Gabrielle, Geneviève, Michel, Jean, Nicolas), sendo dois destes formados no circo (Julie e Louise) e cinco em escolas profissionais circenses. $O$ objetivo do coletivo Passion é resgatar a dimensão humana do circo a partir de diferentes compreensões de como o sujeito contemporâneo constrói o espaço urbano da cidade. Com dez espetáculos produzidos, o circo canadense é considerado referência mundial no campo organizacional das artes do circo, inclusive pela organização pesquisada no Brasil.

\subsection{LÓGICAS PROFISSIONAIS: A FORMAÇÃO DOS ARTISTAS CIRCENSES}

No Canadá existe uma ampla rede de formação profissional dos artistas de circo composta por escolas ou associações que são reconhecidas oficialmente pelo governo local. A província que apresenta a mais antiga e maior rede de organizações voltadas para a formação de artistas de circo é de Quebeque, onde também se localiza o Cirque du Soleil. Deste modo, os artistas que ingressam nas organizações circenses já possuem formação em alguma técnica circense e o foco no cotidiano de trabalho é o desenvolvimento da capacidade de criação dos espetáculos, conforme podemos observar no seguinte excerto do diário de campo:

A tarde de trabalhos hoje foi de muitas atividades cênicas, ao contrário da maioria dos outros dias em que estas atividades eram realizadas no turno da manhã. Carine comentou que as 
coisas estavam fluindo, então eles optaram por continuar o trabalho. Até mesmo Joseph que havia chagado as $16 \mathrm{~h}$ para os treinos acrobáticos, hoje, ficou assistindo tudo sentado ao lado da equipe técnica. Julie e Pierre estavam sentados em frente ao palco conversando. Michel então chama Julie e pergunta: Olhe o que você acha dessa alteração que fizemos. $\mathrm{E}$ continuou explicando o que eles haviam pensado conjuntamente em fazer. Em nenhum momento, Julie interveio nas falas dos artistas. Tão pouco, Pierre interveio, visto a demanda ter sido diretamente para Julie. Ela olhava atentamente e observava as considerações de Michel e ao final comentava: Ok, agora faz pra eu ver. Ela senta-se ao lado de Pierre e os dois começam a desenhar no ar as possibilidades de movimento e possíveis alterações. Eles raramente utilizavam palavras para discutir o que fazer. Predominantemente, conversavam pelos desenhos dos movimentos que realizavam no ar. Julie parecia ter muito mais uma posição de interlocutora no processo de criação dos artistas. (DIÁRIO DE CAMPO, 22 DE AGOSTO DE 2013).

A lógica profissional no circo canadense é focada no fortalecimento das relações entre artistas e diretores para o desenvolvimento do processo criativo dos espetáculos, visto que o domínio da técnica circense é produzido fora do ambiente organizacional. Nesse caso a competência técnica não é um objetivo a ser alcançado por esses artistas, é um requisito, e já se pressupõe que os membros de uma organização como essa tenham suas habilidades desenvolvidas quando ingressam nesse ambiente. $\mathrm{O}$ foco recai na produção dos espetáculos e na habilidade criativa de seus artistas.

\title{
6.2 LÓGICAS DE MERCADO
}

De acordo com o diretor de pesquisa da École Nationale de Cirque de Montréal, o Passion "bateu muita cabeça" até conseguir alguém que conseguisse incorporar a dimensão "mercado" de forma efetiva no processo de organização do circo (DIÁRIO DE CAMPO, 23 DE SETEMBRO DE 2013). Esse alguém é Jean, 0 atual diretor geral do coletivo. Jean foi professor do Departamento de Ciências Políticas em uma Universidade em Montréal, até que foi convidado por uma das artistas do circo para trabalhar com eles. A lógica de mercado é incorporada ao processo de criação e produção dos espetáculos circenses por meio da representação de práticas culturais da localidade onde o circo irá se apresentar:

\begin{abstract}
Geneviève afirmou antes do início das apresentações que hoje somente seriam apresentados os números e cenas que foram adaptados para a turnê no México. As músicas utilizadas eram com melodias latino-americanas. Entretanto, na cena em que há mais movimentos acrobáticos percebi uma batida de samba com música eletrônico o que produziu uma sonoridade muito boa como já havia escutado de alguns artistas brasileiros ainda quando eu residia no Brasil. Uma das cenas que mais me chamou atenção foi a de mão a mão. A cena era de um casal sentado no sofá na sala de televisão de uma casa. Eles brigavam pela posse com controle remoto, pois o marido insistia em assistir uma partida de futebol enquanto a mulher perseverava em manter a televisão no canal de novelas. As narrações destes dois momentos eram em espanhol. A disputa do casal em cena acaba quando na passagem pelo canal televisivo que representava a transmissão de uma partida de futebol um gol do México sobre a seleção Brasileira sela a vitória dos mexicanos sobre os brasileiros nas Olímpiadas de verão do ano de 2012. Apesar de eu não ter gostado do final da cena, por ser uma convicta admiradora do futebol de meu país, as adaptações ficaram muito boas, por eles trabalharem no espetáculo dois aspectos culturais muito presentes no México: novela e futebol. Além de colocar em debate as questões de gênero sobre os hábitos televisivos dos países latino-americanos. Enviei, então, um e-mail para Nicole comentando sobre a pertinência das escolhas realizadas. (DIÁRIO DE CAMPO, 25 DE MAIO DE 2013).
\end{abstract}

A lógica de mercado se insere no contexto organizacional circense canadense no intuito de ampliação do espaço de atuação do circo. Para tanto, questões socioculturais são consideradas pelos diretores da organização para a inserção em mercados emergentes, especialmente da América Latina, 
devido ao contexto macroeconômico de crise na Europa e nos Estados Unidos que eram, até então, foco de atuação dos circos canadenses.

A literatura sobre a lógica de mercado reforça esse achado, tendo em vista que essa lógica se apresenta como coerente e convergente com os objetivos dessa organização circense. As práticas de trabalho deverão ter seu foco em particularidades de continentes ou de países que se pretendem alcançar, por meio da observação de seus costumes, crenças, valores e outros aspectos culturais, sociais e econômicos. A lógica de mercado prevê uma adaptação do ambiente organizacional à medida que os objetivos da organização são construídos socialmente por seus membros.

\subsection{LÓGICAS ESTATAIS}

A principal via de fomento dos circos no Canadá é o Estado e é na província de Quebeque onde existe a maior destinação de verbas para o setor artístico (CANADÁ, 2013). O governo quebequense é o principal financiador das escolas de circo, fomenta a capacitação profissional artística por meio de bolsas a projetos dos artistas e, também, apresenta linhas específicas de financiamento das atividades das organizações que representam os artistas (SAIRE \& DALGIE, 2012). Apesar disso é possível observar que a arte circense ainda não é 0 setor que apresenta 0 maior investimento financeiro do governo.

Uma das principais áreas de investimento do governo canadense é o processo de internacionalização dos circos (Tabela 1) e a organização em estudo é influenciada por esta lógica na definição dos mercados onde irá atuar, especialmente fora do território canadense. Com efeito, historicamente, outro aspecto destacado nas práticas de organização do coletivo é a sua intensa internacionalização que limita seu deslocamento na província de Quebeque, como pode ser observado na fala de uma das gestoras de circos entrevistadas na cidade de Quebeque: "apesar de o coletivo ter crescido muito nos últimos anos eles nunca fizeram temporada na cidade de Quebeque. Eles ficam muito mais por outros países, são mais internacionalizados" (DIÁRIO DE CAMPO, 6 DE JULHO DE 2013). É preciso destacar que, após a realização desta entrevista, ainda no ano de 2013, o coletivo realizou sua primeira temporada de espetáculos na cidade de Quebeque, pois, de acordo com os artistas circenses, do ponto de vista simbólico, é importante que as organizações circenses se apresentem nessa cidade, considerada como berço de artistas de circo no Canadá.

Tabela 1 - Financiamentos do CALQ para o circo entre os anos de 2008 e 2013

\begin{tabular}{c|c|c|c|c|c|c|c|c|c}
\hline Financiamento & $\begin{array}{c}\mathbf{2 0 0 8 -} \\
\mathbf{2 0 0 9}\end{array}$ & $\begin{array}{c}\mathbf{2 0 0 9 -} \\
\mathbf{2 0 1 0}\end{array}$ & $\mathbf{( \% )}$ & $\begin{array}{c}\mathbf{2 0 1 0}- \\
\mathbf{2 0 1 1}\end{array}$ & $\mathbf{( \% )}$ & $\begin{array}{c}\mathbf{2 0 1 1 -} \\
\mathbf{2 0 1 2}\end{array}$ & $\mathbf{( \% )}$ & $\begin{array}{c}\mathbf{2 0 1 2}- \\
\mathbf{2 0 1 3}\end{array}$ & $\mathbf{( \% )}$ \\
\hline $\begin{array}{c}\text { Espetáculos em } \\
\text { Quebeque }\end{array}$ & 56660 & 41000 & $-27,6$ & 131700 & 221,2 & 76500 & $-41,9$ & 96020 & 25,5 \\
\hline $\begin{array}{c}\text { Difusão fora de } \\
\text { Quebeque }\end{array}$ & 108000 & 197000 & 82,4 & 218590 & 10,9 & 245750 & 12,4 & 229900 & $-6,4$ \\
\hline
\end{tabular}

Fonte: CALQ (2013).

A lógica estatal tem grande influência nas práticas de organização e de profissionalização dos artistas circenses canadenses, especialmente via financiamento do processo de internacionalização das organizações circenses canadenses. Com isso, ocorre uma dinâmica de difusão das "maneiras de fazer" circos canadenses que influenciam as práticas artísticas em todo mundo. No Canadá, o Estado se caracteriza como forte influenciador da disseminação da cultura circense, dentro e fora de seu país de origem. Como consequência disso, as organizações circenses canadenses são fortalecidas e ganham legitimidade perante seus pares e seu público em qualquer parte do mundo no qual a arte de circo é apreciada. 


\section{DISCUSSÃO E CONCLUSÕES}

Tendo em vista o fato de que lógicas são instanciadas em contextos específicos (DUNN \& JONES, 2010), procuramos responder nessa pesquisa a seguinte pergunta: como múltiplas lógicas institucionais são articuladas na constituição do circo contemporâneo? Para tanto, procuramos responder à questão, realizando um estudo etnográfico no Brasil e no Canadá, a fim de compreender como as lógicas institucionais configuram a constituição do circo contemporâneo, destacando as alterações das práticas de organização nesses campos organizacionais.

Entendemos que as profissões estão frequentemente sujeitas a lógicas múltiplas, porque elas operam dentro de múltiplas esferas institucionais (DUNN \& JONES, 2010), assim em uma mesma profissão é possível coexistirem duas ou mais lógicas institucionais. A partir do estudo desenvolvido em dois contextos culturais (Brasil e Canadá), foi possível identificar três lógicas institucionais predominantes nestes locais, porém que se constituem com base em diferentes práticas, conforme pode ser observado no Quadro 1:

Quadro 1: Lógicas institucionais e práticas organizacionais no campo organizacional do circo contemporâneo no contexto Brasil-Canadá

\begin{tabular}{|c|c|c|}
\hline $\begin{array}{c}\text { Lógicas } \\
\text { institucionais }\end{array}$ & Práticas circenses brasileiras & Práticas circenses canadenses \\
\hline $\begin{array}{l}\text { Lógicas } \\
\text { profissionais }\end{array}$ & $\begin{array}{l}\text { Práticas de habilidades técnicas. } \\
\text { Práticas de relacionamento entre os artistas e } \\
\text { os diretores. }\end{array}$ & $\begin{array}{l}\text { Práticas de criatividade. } \\
\text { Práticas organização setorial. }\end{array}$ \\
\hline $\begin{array}{l}\text { Lógicas de } \\
\text { mercado }\end{array}$ & $\begin{array}{l}\text { Práticas de hibridização artística. } \\
\text { Práticas de diversidade cultural. } \\
\text { Práticas de ampliação de espaço de atuação. }\end{array}$ & $\begin{array}{c}\text { Práticas de hibridização artística. } \\
\text { Práticas de diversidade cultural. } \\
\text { Práticas de ampliação de espaço de atuação. }\end{array}$ \\
\hline Lógicas estatais & Práticas de ocupação do espaço da cidade. & Práticas de internacionalização. \\
\hline
\end{tabular}

Fonte: Dados da pesquisa

Em relação à profissão circense no Brasil, as práticas de habilidades técnicas, considerando que as lógicas emergem em circunstâncias e contexto histórico específicos, constituem-se e são constituídas nos relacionamentos sociais imersos nas organizações circenses. No Brasil, a presença de escola de circo para a formação de profissionais ligados a essa arte ainda é incipiente. Por isso, as práticas profissionais destacaram o desenvolvimento de habilidades técnicas como essencial para a constituição da organização, bem como da produção dos espetáculos. Apesar de os artistas participarem dos processos de criação, inicialmente é necessária a formação e a capacitação técnica dos sujeitos artistas no cotidiano do circo. As lógicas profissionais não apenas denotam um padrão normativo inerente à profissão, como também carregam um padrão cultural-cognitivo no qual crenças, valores e significados são compartilhados e reproduzidos.

No Canadá as lógicas profissionais estão atreladas especialmente à criação de novos espetáculos, posto que a profissionalização dos artistas ocorre antes da sua entrada no circo. A habilidade técnica não é um critério de avaliação desses artistas para seu ingresso em uma organização circense, e sim um requisito mínimo para participar de uma seleção.

As lógicas de mercado, tanto no Brasil quanto no Canadá, têm em si um significado de transformação do outro (público), especialmente quando da ampliação do espaço de atuação da arte circense. As lógicas de mercado estão associadas às práticas culturais locais, mas também aos fatores sociais e econômicos, tendo em vista que os objetivos da organização estão sujeitos às modificações necessárias e adaptações de acordo com o contexto e o ambiente no qual estão inseridas. 
No Brasil, as lógicas estatais vinculam-se às relações (e/ou disputa) de poder (do governo local e empresas) e interesses políticos que influenciam a ocupação do espaço da cidade pelas organizações circenses. A lógica estatal do Canadá se caracteriza especialmente pelo apoio do governo que promove e financia as escolas circenses e a capacitação dos artistas. A profissionalização dos artistas de circos canadenses é fortemente afetada pela lógica estatal. Nesse contexto, o Estado canadense também age como financiador da internacionalização das organizações circenses, contribuindo para o reconhecimento dessas organizações em outros países.

A contribuição do nosso trabalho reside especialmente no fato do mesmo ter foco no estudo de lógicas institucionais em organizações circenses. Primeiro, porque a abordagem de lógicas ainda é, no institucionalimo, um assunto que apresenta muitas lacunas e que precisa de um esforço maior nas pesquisas para a compreensão do tema. Segundo, porque pesquisas em organizações circenses parecem ser incipientes na área da Administração e de pouco interesse de pesquisadores de estudos organizacionais, se considerarmos a quantidade de estudos desenvolvidos nesses ambientes. Terceiro, porque o estudo das múltiplas lógicas fornecem entendimento sobre como a cultura de uma organização e sua forma de gestão podem ser afetadas por tais lógicas. E, por fim, entendemos que o estudo de lógicas em duas regiões geográficas diferentes (considerando Brasil e Canadá) possibilita comparar semelhanças e/ou diferenças existentes.

No contexto canadense, o campo organizacional circense apresenta diversas escolas e organizações resposáveis pela formação técnica dos artistas de circo. Por isso, ao ingressarem nas organizações os artistas centram suas práticas no desenvolvimento de processos criativos e de produção de espetáculos. Com efeito, o tempo de preparação e de produção de um espetáculo no Canadá é menor do que o realizado no Brasil. Além disso, a profissionalização dos artistas canadenses não é centralizada na dimensão técnica, mas, também, nos processos de organização dos circenses em espaços representacionais de seus interesses no campo artístico e econômico, a exemplo da En Piste.

O equilíbrio relativo entre as lógicas plurais de uma profissão pode regular conflitos sobre a competência, e ainda atacar o cerne do que significa ser um profissional, conforme mencionam Dunn e Jones (2010). É por isso que as lógicas profissionais se constituem a partir de diferentes práticas nos contextos analisados, visto que, de acordo como a dinâmica sociocultural, bem como com os arranjos de diferentes atores sociais, sejam estes indivíduos ou organizações, as lógicas se constituem, reproduzem e se alteram.

Conforme observamos nesse trabalho, as profissões incorporam lógicas conflitantes com as organizações, e os mercados incorporam lógicas que são complementares às corporações e aos seus objetivos (THORNTON, 2002). É por isso que, para os artistas circenses, os mercados artísticos são produzidos a partir das relações das organizações como outros atores organizacionais, especialmente no que se refere à dinâmica de ocupação do espaço urbano, que produz lugares para as apresentações, bem como de atuação do Estado. Nese sentido, outras categorias profissionais são produzidas a partir destas dinâmica, a exemplo dos produtores culturais ou dos técnicos responsáveis pelos treinamentos dos artistas nos circos.

Sabemos que aqueles que estão em conformidade com a lógica institucional dominante são mais prováveis de alcançarem legitimidade e serem mais competitivos e apresentar maior imunidade quanto às pressões para mudança. Nesse contexto, destacamos a importância da atuação do Estado no campo das artes. As lógicas institucionais estatais foram importantes para determinar a atuação das organizações. No Brasil, o conflito da atuação do circo como o Estado resultou na reconfiguração do campo das artes na cidade, evidenciando como as lógicas de mercado e as práticas organizacionais, pode alterar as relações de forças em um campo organizacional. No Canadá, as lógicas institucionais estatais se constituíram em consonância com os objetivos das organizações, tendo como efeito uma incorporação dos objetivos do Estado às práticas organizacionais do circo. Entretanto, é preciso destacar que as lógicas estatais no campo das artes foram alteradas a partir da ocupação de cadeiras

Revista Alcance - Eletrônica - vol. 23 - n. 4 - out./dez. 2016 
nos espaços representacionais das artes pelos artistas de circo. Com isso, é possível destacar que foram as ações subjacentes às lógicas estatais que possibilitaram sua reconfiguração para adequação do campo organizacional do circo contemporâneo.

Destacamos que o estudo dos dois circos possibilitou a discussão sobre dois campos organizacionais, não excluindo a possibilidade da existência de outros campos dentro do mesmo contexto, que é o circo contemporâneo. $O$ texto ressalta a formação dos campos organizacionais a partir das organizações estudadas, portanto podendo ser ampliado em outros estudos a partir dos debates sobre a formação do campo do circo contemporâneo em outras organizações circenses.

Posto isto, destacamos que as relações entre as lógicas institucionais e as práticas de constituição dos campos organizacionais podem ter como efeito a emergência de novas categorias profissionais, a exemplo da atuação dos produtores culturais na seleção de novos artistas circenses, bem como na dinâmica de ocupação do espaço urbano da cidade, especialmente no contexto em análise, pela característica de mobilidade dos circos para a difusão da arte ou pelas práticas de internacionalização promovidas pelo Estado.

\section{REFERÊNCIAS}

ARAÚJO, J. M. Crise no Picadeiro. Revista Problemas Brasileiros, n. 372, p. 17-18, 2005.

ÁVILA, F. S. Território circense. 131f. Dissertação. Programa de Pós-Graduação em Geografia. Universidade Estadual Paulista Júlio de Mesquita Filho (UNESP-Presidente Prudente), Presidente Prudente, São Paulo, 2008.

BOUDREAULT, J. L'annuaire Théâtral. Revue Québécoise D'études Théâtrales, v. 32, p. 22-36, 2002.

CANADA. GUVERNEMENT DU CANADA. Histoire et patrimoine. Disponível em < http://canada.ca/fr/services/culture/histoire.html>. Acessado em 10 de agosto de 2013.

COOK, P. M. A. G. National cultures and popular theatre: four colletive companies in Quebec and Newfoundland. Dissertação. Programa de Pós-Graduação em Artes. Carleton Universiy, Ottawa, Ontário, 1986.

COSTA, M. C.; MELLO, C. M. Mudança e lógicas institucionais: panorama e proposta de conciliação entre três diferentes abordagens institucionalistas. In: VII ENEO - Encontro de Estudos Organizacionais da ANPAD, 2012, Curitiba. Anais... Rio de Janeiro: ANPAD, 2012.

COSTA, M. M. F. A. 0 velho-novo circo: um estudo de sobrevivência organizacional pela preservação dos valores institucionais. 204f. Dissertação (Mestrado em Administração) - Programa de Pósgraduação em Administração Pública da Escola Brasileira de Administração Pública da Fundação Getúlio Vargas, Rio de Janeiro, 1999.

COSTA, M. M. F. A. O velho-novo circo: um estudo de sobrevivência organizacional pela preservação dos valores institucionais. In: ENCONTRO NACIONAL DOS PROGRAMAS DE PÓS-GRADUAÇÃO EM ADMINISTRAÇÃO. 24, Florianópolis, 2000. Anais... Rio de Janeiro: ANPAD, 2000. 1 CD-ROM.

DACIN, M. Tina; OLIVER, Christine; ROY, Jean-Paul. The legitimacy of strategic alliances: an institutional perspective. Strategic Management Journal, v.28, n. 2, 2007.

DUNN, B.; JONES, C. Institutional logics and institutional pluralism: the contestation of care and science logics in medical education 1967-2005. Administrative Science Quarterly, v. 55, p. 114-149, 2010.

FAGOT, S. Le cirque: entre culture du corps et culture du risque. Paris: Harmattan, 2010.

FONTANA, A; FREY, J. H. (2005). Interviewing: the art of science. In: DENZIN, N. K.; LINCOLN, Y. S. (org). Handbook of Qualitative Research. London: Sage, p. 695-728. 
FRIEDLAND, R.; ALFORD, R. R. Bringing society back in: symbols, practices, and institutional contradictions. In : W. W. POWELL, W. W.; DiMAGGIO, P. J. (Eds.). The new institutionalism in organizational analysis. London: University of Chicago Press, 1991, p. 232-263.

Garcia, M. C. Artists de cirque contemporain. Paris: La dispute, 2011.

LAWRENCE, T. B.; PHILIPS, N. From Moby Dick to Free Willy: macro-cultural discourse and institutional entrepreneurship in emerging institutional fields. Organization, v. 11, n. 5, p. 689-711, 2004.

LANSBURY, M. A Tale of two cities: competing logics and practice variation in the professionalizing of mutual funds. Academy of Management Journal, v. 50, p. 289-307, 2007.

LEGAULT, A. C. L'affirmation culturelle québécoise dans le mouvement du jeune théâtre: grand cirque ordinaire et théâtre du même nom (1969-1971). 2012. 133f. Dissertação. Programa de PósGraduação em Artes - Département de Théâtre, Faculté des Arts, Université d'Ottawa, Ottawa, 2012.

LESLIE, D.; RANTISI, N. M. Creativity and Place in the Evolution of a Cultural Industry: the Case of Cirque du Soleil. Urban Studies, v. 48, n. 9, p. 1771-1787, 2010.

MARCUS, G. E. What is at stake - and is not - in the idea and practice of multi-sited ethnography. Camberra Anthropology, v. 22, n. 2, p. 6-14, 1999.

MELLO, C. M. Abordagens e procedimentos qualitativos: implicações para pesquisas em organizações. Revista Alcance, v. 21, n. 2, p. 324-349, 2014.

MEYER, J.; ROWAN, B. Institutionalized organizations: formal structure as myth and ceremony. In: POWELL, W.; DIMAGGIO, P. (ed). The new institutionalism in organizational analysis. Chicago: The University of Chicago Press, 1991, pp. 41-621.

MUTCH, A. Reflexivity and the institutional entrepreneur: a historical exploration. Organization Studies, v. 28, n. 7, p. 1123-1140, 2007.

NEPOMUCENO FILHO, L. C. Vai, vai, vai começar a brincadeira: em meios a uma gargalhada tradicional, algumas notas históricas do desenvolvimento do circo no Brasil. Revista Inter-Legere, v. 4, p. $288-293,2009$.

OFEN, J. L. Portrait of a circus girl. Ethnography, v. 11, n. 3, p. 473-484, 2010.

PARKER, M. Organizing the Circus: The Engineering of Miracles. Organization Studies, v. 32, n. 4, p.555-569, 2011.

REAY, T.; HINNINGS, C. Managing the rivalry of competing institutional logics. Organization Studies, v.30, n.6, p.629-652, 2009.

ROCHA, G. O circo no Brasil - estado da arte. BIB. Revista Brasileira de Informação Bibliográfica em Ciências Sociais, v. 70, p. 51-70, 2010.

ROSSETTO, C. R.; ROSSETTO, A. M. Teoria institucional e dependência de recursos na adaptação organizacional: uma visão complementar. Revista de Administração de Empresas, v. 4, n. 1, p. 1-26, 2005.

SAIRE, P. O.; DALGIE, P. Planification sectorielle des arts du cirque. En Piste: Montréal, 2012.

SACCHI, W. A Identidade Saltimbanco. 117f. Dissertação. Programa de Pós Graduação em Multimeios, da Universidade Estadual de Campinas (UNICAMP), Campinas, São Paulo, 2009.

SCOTT, W. R. Institutions and Organizations. Londres: Sage, 2001.

SELZNICK, P. Institutionalism "old" and "new". Administrative Science Quarterly, v. 41, p. 270-277, 1996. 
SEWELL, W. H. A theory of structure: duality, agency, and transformation. American Journal of Sociology, v. 98, n. 1, p. 1-29, 1992.

SHERER, P. D.; LEE, K. Institutional change in large law firms: a resource dependency and institutional perspective. Academy of Management Journal, v. 45, n. 1, 2002.

SOUZA, M. M. P.; CARRIERI, A. P. Racionalidades no fazer artístico: estudando a perspectiva de um grupo de teatro. Revista de Administração de Empresas, v. 51, n. 4, p. 382-395, 2011.

SUCHMAN, M. C. Managing legitimacy: strategic and institutional approaches. Academy of Management Review, v. 20, n. 3, p. 571-610, 1995.

SUDDABY, R. Challenges for institutional theory. Journal of Management Inquiry, v. 19, n. 1, p. 1420, 2010.

THORNTON, P. H. ; OCASIO, W. ; LOUNSBURY, M. The institutional logics perspective. Oxford: Oxford University Press, 2012.

THORNTON, $\mathrm{P}$. The rise of the corporation in a craft industry: conflict and conformity in institutional logics. Academy of Management Journal, v. 45, n. 1, p. 81-101, 2002.

THORNTON, P. Markets from culture: institutional logics and organizational decisions in higher education publishing. California: Stanford University Press, 2004.

THORNTON, P.; OCASIO, W. Institutional Logics. In: GREENWOOD, R.; OLIVER, C.; SAHLIN, K.; SUDDABY; R. (Orgs.). The Sage Handbook of Organizational Institutionalism. London: Sage, 2008, p. 99-129.

ZUCKER, L. G. Institutional theories of organization. Annual Review of Sociology, v. 13, p. 443-464, 1987.

ZUCKER, L. G. The role of institutionalization in cultural persistence. In: POWELL, W.; DIMAGGIO, P. The new institutionalism in organizational analysis. Chicago: The University of Chicago Press, 1991, pp. 83-107. 